\title{
The effect of gender on the exclusive breastfeeding practices in the first month of life
}

\author{
Naintina Lisnawati, Dina Rahayuning Pangestuti*, Wardatus Zahroh \\ Department of Public Health Nutrition, Faculty of Public Health, Diponegoro University, Indonesia
}

\begin{abstract}
Exclusive breastfeeding practice (EBP) has a main role in growth and development of infant. Research show that EBP in the first month of life influenced by many factors. Therefore, this study aimed to identified factors that related to EBP of infants in the first month of life. A cross sectional study was conducted on 35 breastfeeding mothers in Kedungmundu Subdistrict, Semarang, Central Java Province, Indonesia. Mother's general characteristic and prelacteal feeding were collected by structured questionnaires. Moreover, anthropometric measurements such as midupper-arm circumference (MUAC), height, body weight, and body fat percentage were also collected. Data analysis used Chi-square, Fisher Exact, Mann-whitney, and Logistic Regression Test. The results showed that all of infants were born in normal birth weight. MUAC, body mass index (BMI), body fat percentage, and median parity of mothers were $26 \mathrm{~cm}, 23.2 \mathrm{~kg} / \mathrm{m}^{2}$, $29.6 \%$ and 2 children, respectively. This study also found that mothers who breastfeed their babies exclusively in the first month of life were only $44 \%$, and gender was significantly related to EBP $(p=0.026) .65 \%$ non EBP mothers have a male infant which is they need large amount of breast milk than female. In conclusion, gender effect on the availability of breast milk on breastfeeding mothers.
\end{abstract}

\section{Introduction}

Exclusive breastfeeding practice is recommended for infants aged 0 to 6 months by giving only breast milk without additional food or drink, except medicine and vitamin recommended by doctor [1]. It has been known that exclusive breastfeeding has many benefits for the health of infants, including protecting against infections such as diarrhea, respiratory tract infections [2] and for the growth of infants [3]. Percentage of exclusive breastfeeding practices both globally and nationally still cannot reach optimal target. Research in both developed and developing countries show various factors that influence the practice, such as socialeconomic conditions, maternal education level, maternal age, parity, mode of birthing, maternal employment status, media exposure and support from family, professional health, social networks and policies, also supporting facilities, whether at work or in public facilities [4]. Physical and social factors around mother are called environmental factors. An environmental attribute that is found to play an important role to enable mothers to breastfeed their babies, especially to ensure exclusivity is an environmental factor that start from

* Corresponding author: dinapangestuti@lecturer.undip.ac.id 
hospital environment and health services (place of birth), home environment and friends, work environment and community [5].

Based on Riset Kesehatan Dasar (Riskesdas) data in 2018, the percentage of exclusive breastfeeding in Central Java in the last 24 hours lower than target in Indonesia (37.3\%). Compared to data from Survei Demografi dan Kesehatan Indonesia (SDKI) in 2017 show that $52 \%$ children under 6 months got exclusive breastfeeding. Median duration of exclusive breastfeeding is 3 months. While, percentage of children who didn't get breastfeed from their mothers increase from $8 \%$ in 2012 to $12 \%$ in 2017. However, Central Java Province only reached $34.38 \%$, while Semarang City in 2013 amounted to $61.2 \%$. A systematic review show that exclusive breastfeeding in the first six months of life in Brazil influenced by place of residence, maternal age, maternal education, maternal labor, age of the child, use of a pacifer, and financing of primary health care [6]. Study in Germany show that breastfeeding duration influence by many factors, include maternal age, supplementary feeding, single parent status, maternal educational status, breastfeeding problems and partner's attitude towards breastfeeding. Subjects of this study were mothers. Mothers were classified as longterm breastfeeding and short-term breastfeeding [7]. Moreover, one of study in Ethiopia also show that prelacteal feeding also influenced of mothers to breastfeed exclusively [8].

Babies who do not get breast milk exclusively have a low immune system so they are at risk of suffering various diseases, such as pneumonia and respiratory tract infections. In addition, when they grow into adults will be more at risk of developing degenerative diseases and have a low intelligence quotient (IQ) [9]. Exclusive breastfeeding should be monitored thoroughly in accordance with the specified time target. Previous research has mostly examined the factors that influence the practice of breastfeeding at the age of 0-6 months. Whereas the first month period of life is an important period in the production of breast milk quality. In addition, no previous research has focused on observing the practice of breastfeeding in urban areas. Kedungmundu Sub-district, Semarang City is an urban area with good economic and governance characteristics. Therefore, this study aims to identify factors related to the failure of breastfeeding practices in the first month of life in Kedungmundu Sub-district, Semarang City, Central Java Province, Indonesia.

\section{Methods}

\subsection{Research design and data collection}

This research was an observational study with Cross-Sectional design. The subjects of research were breastfeeding mothers who have babies aged 0-1 months in Kedungmundu Sub-district, Semarang, Central Java. Babies born must be in a healthy state or have no difficulty in breastfeeding, not twins, and have a normal birth weight $(>2.5 \mathrm{~kg})$. Subjects had a Maternal And Child Health Handbook (KIA), and was still breastfeeding at the time of the research.

Subject's characteristic data was collected through a validated questionnaire. Subject's characteristic data include age, parity, family structure, per capita income, level of education, and working status of mothers. In addition, anthropometric data (body weight, height, midupper-arm circumference (MUAC), body mass index (BMI), body fat percentage) and prelacteal feeding were also collected. Body weight was measured by digital scales, body height by microtoise, MUAC by MUAC ribbon, and percent body fat by Bio Impedance Analyzer (BIA). Questionnaire regarding prelacteal feeding was asked to the subject by confirming the food given to the baby beside breast milk shortly after birth and during the last 24 hours. 
Age of mothers were categorized as productive (between 15-64 years) and nonproductive age (less than 15 years and 65 years and over) [10]. Family structure also classified as nuclear and extended family. Nucelar family consist of husband, wife and their unmarried children, or one parent with his or her children. While, extended family consist of husband, wife, and their married children [11]. Per capita income was calculated based on the total income compared to the regional minimum wage standard divided by the number of family members. It categorized as low (under regional minimum wage) and high (based on regional minimum wage and over). The body fat percentage of mothers was categorized as obese if $\geq 30 \%$ [12]. BMI was classified according Asian population standard using WHO classification, i.e. $<18.5 \mathrm{~kg} / \mathrm{m}^{2}$ as underweight, $18.5-22.9 \mathrm{~kg} / \mathrm{m}^{2}$ as normal, $\geq 23 \mathrm{~kg} / \mathrm{m}^{2}$ as overweight, and $23-24.9 \mathrm{~kg} / \mathrm{m}^{2}$ as having a risk of obese [12]. Protein energy malnutrition (PEM) of mothers was categorized according to MUAC standard $<22 \mathrm{~cm}[13,14]$. Moreover, the calculation of birth length between $48-52 \mathrm{~cm}$ was categorized as normal [15].

\subsection{Data analysis}

Data were analyzed using computer software in univariate, bivariate, and multivariate. Univariate analysis includes: mean, median, percentage, minimum, maximum, and standard deviation (SD). The normality test was carried out before bivariate analysis using the Shapiro-Wilk test to see the homogenization of collected data. Bivariate analysis was performed to analyze the association of subject's characteristics, anthropometry measurements, and prelacteal feeding to the practice of exclusive breastfeeding at the age of 0-1 months. Data analysis using Chi-Square, Fisher Exact, Mann-Whitney, and Logistic Regression Test. The probability level $(\mathrm{p}<0.05)$ was used as a threshold for significance.

\subsection{Ethical approval}

Subjects were briefed about purpose, procedure, and assessment activities of the study. Subject's participation was voluntary and agreement to participate was documented by signing informed consent form. Ethical approval for study was provided by Ethics Committee of Health Research, Faculty of Public Health, Diponegoro University (No.222/EC/FKM/2016). All of subject's identities and details were kept confidential.

\section{Findings}

\subsection{Subject's characteristics}

In this study, 36 breastfeeding mothers and their babies were recruited as research subjects. Most of the subjects are housewives, in productive age and consist of nuclear families. Based on Table 1, mean of mother's age was $29.1 \pm 4.9$ years so it was included in the productive age. The percentage of working mothers $(22.2 \%)$ was lower than not working $(63.9 \%)$ with missing data at $13.9 \%$. Mother's education level was classified into 2 categories, i.e. lowmoderate and high. If the subject completed their education from elementary to high school then it was categorized as low-moderate. However, if the subject completed her education to college then it was categorized as high. Most of the education levels of the subjects in this study were low-moderate (72.2\%). The calculation of per capita income of subjects showed that subjects with low per capita income $(44.4 \%)$ were lower than subjects with high per capita income (52.8\%). It was because of Kedungmundu Sub-district is an urban area whereas the economic governance tends to be better than in rural areas. Median age of infants at the time of the study was 3 weeks $(<1$ month) with the percentage gender of male $(52.8 \%)$ 
higher than female (47.2\%). The average birth weight and birth length of infants were 3119.4 $\pm 32.8 \mathrm{~g}$ and $49 \mathrm{~cm}$, respectively, so it were classified as normal.

Table 1. General Description of Mothers and Infants Characteristic

\begin{tabular}{lc}
\hline \multicolumn{1}{c}{ Variables } & Result \\
\hline Mothers (n=36) & $29.1 \pm 4.9$ \\
Age (year) (mean \pm SD) & $2.0(0-4)$ \\
Parity (median, min-max) & \\
Family structure & $16(44.4)$ \\
$\quad$ Extended (n, \%) & $20(55.6)$ \\
$\quad$ Nuclear (n, \%) & \\
Level of education & $26(72.2)$ \\
$\quad$ Low - moderate (n, \%) & $4(11.1)$ \\
$\quad$ High (n, \%) & \\
Working status & $23(63.9)$ \\
$\quad$ Not working (n, \%) & $8(22.2)$ \\
$\quad$ Working (n, \%) & $16(44.4)$ \\
Per capita Income & $19(52.8)$ \\
$\quad$ Low (n, \%) & \\
$\quad$ High (n, \%) & \\
Infants (n=36) & $3.0(1-19)$ \\
Age (week) (median, min-max) & \\
Gender & $19(52.8)$ \\
$\quad$ Male (n, \%) & $17(47.2)$ \\
$\quad$ Female (n, \%) & \\
Anthropometry & \\
$\quad$ Birth Length (cm) (median, min-max) & $49(46-53)$ \\
$\quad$ Birth Weight (g) (mean \pm SD) & $3119.4 \pm 32.8$ \\
\hline
\end{tabular}

\subsection{Breastfeeding practices}

Related to prevalence of exclusive breastfeeding, accuracy in interpreting results is needed because the definition of exclusive breastfeeding in several studies varies according to the method of data collection. Providing breast milk without the addition of water, tea, herbs or other types of food with the exception of vitamins, mineral supplements and medicines is the definition of exclusive breastfeeding recommended by WHO [16]. Food recall 24 hours before interview about exclusive breastfeeding status was also recommended for use in largescale surveys. However, researchers have seen differences in the prevalence of exclusive breastfeeding using different methods. A modification or additional indicator has been suggested to reduce the limitations of the recall method [17]. The most ideal method in assessing breastfeeding practices exclusively is to monitor the baby from birth to 6 months of age which is the final limit of breastfeeding exclusivity. This method remains by using recall 24 hours before the interview but by following up to 6 months [18]. In this study, practice of breastfeeding by subjects was followed starting from childbirth (infant aged 0 days) to the first month of life. The percentage of exclusive breastfeeding in the first month of life in this study is presented in Figure 1 (Fig. 1.). Based on Figure 1, the data shows that in the first month of life, mothers who exclusively breastfeed their babies were only 16 people $(44.4 \%)$ while 20 people $(55.6 \%)$ of breastfeeding mothers failed to breastfeed exclusively. This condition can be caused by various factors and will be discussed further. 


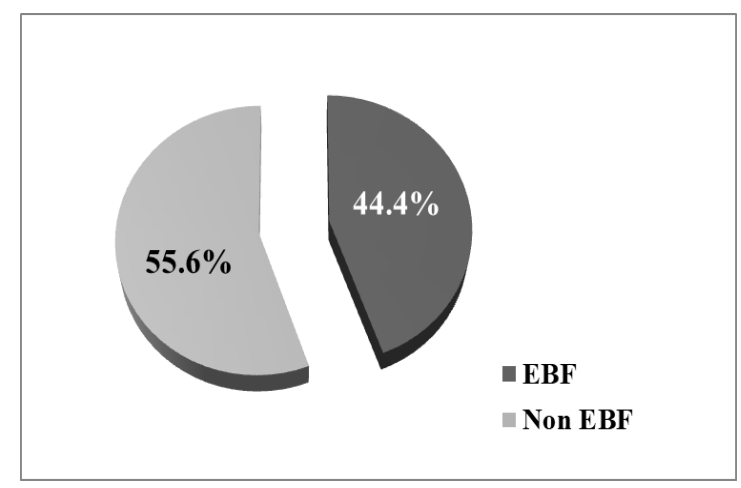

Fig. 1. Comparison of percentage of Exclusive Breastfeeding (EBF) and Non Exclusive Breastfeeding (Non EBF) of Subjects in the first month of life

\subsection{Nutritional status}

Nutritional status is the result of a balance between nutrients that enter the body and its use [19]. The nutritional status of breastfeeding mothers in this study was determined through anthropometric measurements (Table 2).

Table 2. Maternal Anthropometric Characteristics

\begin{tabular}{lc}
\hline \multicolumn{1}{c}{ Variable } & Result \\
\hline Body weight & \\
Before pregnancy (kg) (median, min-max) & $47(37-112)$ \\
During study (kg) (median, min-max) & $53.8(42.4-118.5)$ \\
Body height $(\mathrm{cm})($ mean $\pm \mathrm{SD})$ & $153.8 \pm 4.63$ \\
BMI $\left(\mathrm{kg} / \mathrm{m}^{2}\right)($ median, min-max) & $23.2(17.4-45.1)$ \\
MUAC $(\mathrm{cm})($ median, min-max) & $26(22-44)$ \\
Body fat percentage $(\%)$ (median, min-max) & $29.6(20.8-44.9)$ \\
\hline
\end{tabular}

Based on Table 2, it was found that median weight of subjects before pregnancy was 47 $\mathrm{kg}$ with minimum weight of the subject was $37 \mathrm{~kg}$ and maximum was $112 \mathrm{~kg}$. At the time of study, subject's median weight was $53.8 \mathrm{~kg}$. Median BMI of the subjects in the study was $23.2 \mathrm{~kg} / \mathrm{m}^{2}$ so that it was categorized as having risk of obese. Moreover, median MUAC of subjects reached $26 \mathrm{~cm}$, there were still subjects which was indicated as normal. Median body fat percentage of subjects was $29.6 \%$ and it was also categorized as normal.

\subsection{Factors related to breastfeeding practices}

The practice of breastfeeding is a unique natural process and behavior learned between mothers and their babies. This is influenced by factors that might have a positive or negative influence on the breastfeeding mother's belief. Accurate information and support in the family, community and health care system needed by the mothers to build mother's trust, improve eating techniques and resolve breastfeeding problems faced by the mother. The factors of individual, group and community found by many studies show an association with the practice of breastfeeding [4]. 
Table 3. Factors associated to breastfeeding practice in the first month of life

\begin{tabular}{|c|c|c|c|}
\hline \multirow{2}{*}{ Variables } & \multicolumn{2}{|c|}{ Group } & \multirow[b]{2}{*}{$\mathrm{p}$} \\
\hline & Non EBF & $\mathrm{EBF}$ & \\
\hline \multicolumn{4}{|l|}{ Age of mother } \\
\hline Non productive age (n, \%) & $2(12.5)$ & $1(6.7)$ & $1.000^{\mathrm{b}}$ \\
\hline Productive age (n, \%) & $14(87.5)$ & $14(93.3)$ & \\
\hline Parity (median, min-max) & $1(0-4)$ & $2(1-4)$ & $0.069^{\mathrm{c}}$ \\
\hline \multicolumn{4}{|l|}{ Family structure } \\
\hline Extended $(\mathrm{n}, \%)$ & $12(60)$ & $4(25)$ & $0.036^{* a}$ \\
\hline Nuclear (n, \%) & $8(40)$ & $12(75)$ & \\
\hline \multicolumn{4}{|l|}{ Per capita income } \\
\hline Low $(n, \%)$ & $8(42.1)$ & $8(50)$ & $0.640^{\mathrm{a}}$ \\
\hline $\operatorname{High}(\mathrm{n}, \%)$ & $11(57.9)$ & $11(50)$ & \\
\hline \multicolumn{4}{|l|}{ Education levels of mother } \\
\hline Low-Moderate (n, \%) & $12(80)$ & $14(93.3)$ & $0.598^{b}$ \\
\hline $\operatorname{High}(\mathrm{n}, \%)$ & $3(20)$ & $1(6.7)$ & \\
\hline \multicolumn{4}{|l|}{ Working status of mother } \\
\hline Working $(\mathrm{n}, \%)$ & $3(20)$ & $5(31.2)$ & $0.685^{b}$ \\
\hline Non working (n, \%) & $12(80)$ & $11(68.8)$ & \\
\hline \multicolumn{4}{|l|}{ BMI before pregnancy } \\
\hline Underweight (n, \%) & $4(20)$ & $4(25)$ & $1.000^{\mathrm{b}}$ \\
\hline Non underweight (n, \%) & $16(80)$ & $12(75)$ & \\
\hline \multicolumn{4}{|l|}{ Body fat percentage } \\
\hline Obese $(n, \%)$ & $11(55)$ & $7(43.8)$ & $0.502^{\mathrm{a}}$ \\
\hline Non obese (n, \%) & $9(45)$ & $9(56.2)$ & \\
\hline \multicolumn{4}{|l|}{ MUAC } \\
\hline $\operatorname{PEM}(\mathrm{n}, \%)$ & 0 & $1(6.2)$ & $0.444^{\mathrm{b}}$ \\
\hline Non PEM (n, \%) & $20(100)$ & $15(93.8)$ & \\
\hline \multicolumn{4}{|l|}{ Birth length of infant } \\
\hline Low (n, \%) & $4(20)$ & 0 & $0.113^{b}$ \\
\hline Normal (n, \%) & $16(80)$ & $16(100)$ & \\
\hline \multicolumn{4}{|l|}{ Gender of infant } \\
\hline Male (n, \%) & $13(65)$ & $6(37.5)$ & $0.101^{\mathrm{a}}$ \\
\hline Female (n, \%) & $7(35)$ & $10(62.5)$ & \\
\hline \multicolumn{4}{|l|}{ Prelacteal feeding } \\
\hline Yes $(\mathrm{n}, \%)$ & $11(55)$ & 0 & \\
\hline No $(n, \%)$ & $9(45)$ & $16(100)$ & $0.001^{* \mathrm{c}}$ \\
\hline
\end{tabular}

${ }^{a}$ Chi-Square Test

${ }^{b}$ Fisher Exact Test

${ }^{c}$ Mann-Whitney Test

* Value were significantly associated to failure of exclusive breastfeeding practices in the first month of life; $p<0.05$

According to Table 3, subject's general characteristics consist of age, parity, per capita income, level of education, and working status have no significantly associated to breastfeeding practices ( $p>0.05)$. Similar to general characteristic, anthropometric parameter consist of maternal MUAC, BMI, percent body fat of mother, and birth length of baby, it was also had no significantly associated to the practice of breastfeeding in the first month of life ( $p>0.05)$. From the analysis also showed that family structure and prelacteal feeding were significantly associated to EBF practices, while gender of infant was not related $(p=0.101)$. In this study, multivariate analysis was created to found the variable which is strongly affecting to EBF practices. Family structure, prelacteal feeding, and gender of infant were variables that eligible to run in multivariate analysis. 
Table 4. Logistic regression analysis of factor that affect exclusive breastfeeding practice

\begin{tabular}{lcccccc}
\hline \multicolumn{1}{c}{ Factor } & $\beta$ & $S E \beta$ & $\begin{array}{c}\text { Wald's } \\
X^{2}\end{array}$ & $d f$ & $p$ & $\begin{array}{c}e^{\beta} \\
\text { (odds ratio) }\end{array}$ \\
\hline Constant & 21.529 & $1.065 \mathrm{E} 4$ & 0.001 & 1 & 0.998 & $2.239 \mathrm{E} 9$ \\
Family structure & -2.011 & 1.226 & 2.691 & 1 & 0.101 & 0.134 \\
Prelacteal feeding & -22.947 & $1.065 \mathrm{E} 4$ & 0.001 & 1 & 0.998 & 0.001 \\
Gender of infant & 3.106 & 1.393 & 4.973 & 1 & 0.026 & 22.328 \\
\hline
\end{tabular}

Based on multivariate analysis, gender of infant was the only variable that has strongly affecting exclusive breastfeeding practices of mothers in the first month of life $(\mathrm{p}=0.026$; $\mathrm{OR}=22.328$ ). While, family structure and prelacteal feeding were no strongly affect with probability values of both variables were $\mathrm{p}=0.101$; $\mathrm{OR}=0.134$ and $\mathrm{p}=0.998 ; \mathrm{OR}=0.001$, respectively.

\section{Discussion}

Several studies on maternal characteristics of breastfeeding practices found that not only working mothers had difficulty by not giving breast milk to their babies, but also housewives prefer to choose giving formula milk to their babies. This shows that working status of mothers was no longer the main barrier factor for a mother to continue breastfeeding exclusively for their babies [20]. As shown in Table 1, mothers that recruited as subject, has relatively young babies (median $=3.0$ weeks). It is intended to follow as early as possible to develop exclusive breastfeeding practices until the deadline for succeed, i.e. 6 months until 2 years. However, at the beginning of recruitment, it turned out that more than half had failed exclusively breastfeeding because of various things. A study in Riyadh, Saudi Arabia, showed that the most influential factor in mother's decision to give breast milk exclusively was the support of health workers. The role of health workers in assisting and providing education regarding the practice of breastfeeding after childbirth is proven to be the most significant thing that influences the success of mothers to breastfeed until the age of 6 months [21]. In this study, only $28 \%$ of breastfeeding mothers were recorded as having received postpartum visits from health workers while $72 \%$ of mothers did not receive visits from health workers. This condition certainly influenced mothers in obtaining information about breast milk considering that the majority of mothers (72.2\%) have low-moderate education level where it is very unlikely to access their own information about breast milk, so that in the first month after childbirth there was $55.6 \%$ who failed breastfeeding exclusively.

Prelacteal feeding is a food or drink that is given by mothers to the babies in the first 3 days of childbirth [22]. In this study, prelacteal feeding was one of factor that associated to breastfeeding practices. Total number of breastfeeding mothers who failed to give exclusive breastfeeding was 55\% and all of them were caused by giving prelacteal feeding. The type of prelacteal feeding which given is formula milk provided by mothers. This result is in line with a national survey conducted in 21 regions in Nepal that $1 / 3$ (one third) of samples of breastfeeding mothers were proven to provide prelacteal feeding to their babies. The survey results stated that the history of antenatal examinations has a significant influence on decreasing the prevalence of prelacteal feeding, particularly regarding the role of healthcare professionals who are initiatives in visiting pregnant women when unable to attend antenatal examination [23]. Another factor that can influence the prelacteal feeding is husband's support. A study in Ethiopia showed that husband's support had a two-fold risk in the practice of prelacteal feeding. In Ethiopia, husbands play an important role in making decisions in all aspects of the family, including about feeding babies [7]. This situation is no different from the culture in Indonesia, that the husband is a decision maker in the family. The limitation of 
this study is did not examine qualitatively about the aspects of husband, family, and environmental support for the practice of prelacteal feeding.

Family structure also remain an important role of giving decision of EBF beside husband. In this study, $60 \%$ mothers who failed to breastfeed their babies were include in extended family. One of study in Ethiopia showed that extended family support has significantly associated with initiation of breastfeeding among mothers. Low support for EBF from extended family would affect mother's decision to continue breastfeed their babies exclusively [24]. Another research in Bristol showed that one of extended family support was according to their culture and belief about breastfeeding. Most of them suggested to mothers to give water mixing with sugar to their babies. They belief that by giving this formula, the babies could get extra energy and decrease fatigue [25]. Beside culture and belief, myth about breastfeeding in Indonesia also being one of factor of failure of exclusive breastfeeding practice of mothers. Study in Gunungkidul, Yogyakarta, Indonesia showed that some myths were still occurred such as colostrum wasn't good to babies, and mothers should provide water or tea to babies before giving breastfeed were being factors of failure of EBF practice in the first month of life [26].

Gender of infant was being a variable which was strongly associated to EBF practice according to logistic regression analysis. In this study, 65\% of non EBF mothers had male infant. Study in Bangladesh showed that gender of infant related to duration and frequency of breastfeeding. The study stated that male infant has longer period to breastfeeding. It means that they need high total amount of breast milk than female infant [27]. Another study also found that the EBF score were higher on female than male infant. Male infant had higher demand on breast milk, they usually giving sign by crying and short sleeping duration. This condition often made mothers doesn't have a large amount of breast milk and finally decide to provide another feed to their male babies [28]. Study in Turkey had similar finding, it stated that in urban area, the duration of breastfeeding quite longer to male than female infant. From the study also stated that to fulfill on demanding breast milk for male infant, most pf mothers provide formula milk, that's why the failure of EBF practice of mother also affected by gender of infant [29].

\section{Acknowledgement}

The authors would like to thank all the research subjects who participated in this study and all enumerators who have contributed to the data collection. Gratitude was addressed to Faculty of Public Health, Diponegoro University which provided funds for this study.

\section{References}

1. WHO-UNICEF, Global strategy for infant and young child feeding (2003)

2. S. Arifeen, R.E. Black, G. Antelman, A. Baqui, L. Caulfield, S. Becker, Pediatrics 108 (4), 1-8 (2001)

3. M.S. Kramer, R. Kakuma, The optimal duration of exclusive breastfeeding: A systematic review (WHO, Geneva, 2002)

4. D. Hector, L. King, K. Webb, P. Heywood, NSW Public Health Bulletin 16 (4), 52-5 (2005)

5. M. Chung, G. Raman, T.A. Trikalinos, J. Lau, Breastfeeding Medicine 4 (s1), 17-30 (2009)

6. C.S. Boccolini, M.L. Carvalho, M.C. Oliveira, Rev Saúde Pública 49 (91), 1-15 (2015)

7. M. Dulon, M. Kersting, S. Schach, Acta Paediatra 90 (8), 931-5 (2001) 
8. T. Tewabe, Ethiop J Health Sci 28 (4), 393-402 (2017)

9. C. Binns, D. Forbes, J. Scott, M. Pasalich, B. Symon, M. Bammann, Australian family physicin 41(4), 226-9 (2012)

10. Statistics Indonesia, Dependency ratio (BPS, Indonesia, 2020)

11. R.R. Jay, Javanese villagers: Social relations in rural Modjokuto (1969)

12. N.R. Shah, E.R. Braverman, PLoS ONE 7, e33308 (2012)

13. A. Ferro-Luzzi, W.P. James, British Journal of Nutrition 75 (1), 3-10 (1996)

14. M.T. Alice, K. Dong, M. Deitchier, M. Chung, Z. Maalouf-Manasseh, A. Tumilowicz, C. Wanke, Use of Cutoffs for mid-upper arm circumference (MUAC) as an indicator of predictor of nutritional and health related outcomes in adolescents and adults: A systematic review (FHI360/FANTA, Washington, DC, 2013)

15. Ministry of Health of Indonesia, Guide book for newborn health care based on child protection (2010)

16. WHO, Indicators for assessing breastfeeding practice (1991)

17. H. Mulol, A. Coutsoudis, Int Breastfeed J 13 (19), 1-6 (2018)

18. T.O. Vieira, G.O. Vieira, N.F. de Oliveira, C.M.C. Mendes, E.R.J. Giugliani, L.R. Silva, BMC Pregnancy and Childbirth 2014; 14 (175), 1-9 (2014)

19. R.S. Gibson, Principles of nutritional assessment: 2nd ed, (Oxford University Press, New York, 2005)

20. A. Koosha, R. Hashemifesharaki, N. Mousavinasab, Singapore Med J 49 (12), 1002-6 (2008)

21. A.A. Ahmed, A. Shoshan, Pakistan Journal of Nutrition 6 (4), 318-22 (2007)

22. R. Chaudhary, T. Shah, S. Raja, Health Renaissance 9 (3), 194-200 (2011)

23. S. Bhandari et al, International Breastfeeding Journal 14 (14), 1-17 (2019)

24. G. Tilahun, G. Degu, T. Azale, A. Tigabu, International Breastfeeding Journal 11, 27 (2016)

25. J. Ingram, D. Johnson, N. Hamid, Midwifery, 19 (4), 318-27 (2003)

26. W. Warsiti, L. Rosida, D.F. Sari, Jurnal Ilmiah Keperawatan 15, 1 (2020)

27. R. Ghosh, C.G.N Mascie-Taylor, L. Rosetta, American Journal of Huaman Biology 18 (5), 630-638 (2006)

28. S.S. Yalcin, B.B. Koskonmaz, Breastfeeding Medicine 6 , 4 (2011)

29. N. Yesildal et al, Breastfeeding Practices in Duzce, Turkey, Journal of Human Lactation 24, 4 (2008) 